\title{
Chromosomal inversion polymorphism in 2 marginal populations of the endemic Hawaiian species, Drosophila silvestris
}

\author{
HL Carson ${ }^{1}$, EM Craddock ${ }^{2}$ \\ 1 University of Hawaii, Department of Genetics and Molecular Biology, \\ John A Burns School of Medicine, Honolulu, HI 96822; \\ 2 State University of New York, Division of Natural Sciences, \\ Purchase, NY 10577-1400, USA
}

(Received 9 March 1995; accepted 30 August 1995)

\begin{abstract}
Summary - Chromosomal polymorphisms for 11 inversions from 2 demes of Drosophila silvestris from the volcano Mauna Kea, Island of Hawaii are distributed over 4 of the 5 major chromosome arms. These occur at frequencies from 2 to $70 \%$. Seven of these inversions have been found widely distributed in other populations of this species. The 5 inversions in chromosome 4 were analyzed by a new method that permits the determination of haplotype frequencies of linked inversions and the scoring of genotypes formed by them. This variability appears to persist in a state of balanced polymorphism in these small isolated insular populations and is as great as or greater than that found in comparable demes of continental species.
\end{abstract}

chromosomal variability / small population / island biology / inversion / Drosophila silvestris

Résumé - Polymorphisme d'inversion chromosomique dans 2 populations marginales de l'espèce endémique hawaïenne Drosophila silvestris. Des polymorphismes chromosomiques concernant 11 inversions, observées dans 2 dèmes de Drosophila silvestris du Mauna Kea (île de Hawaï), se répartissent sur 4 des 5 bras chromosomiques principaux. Leur fréquence varie de 2 à $70 \%$. Sept de ces inversions sont largement répandues dans d'autres populations de cette espèce. Les 5 inversions du chromosome 4 ont été analysées selon une méthode nouvelle qui permet de déterminer les fréquences haplotypiques d'inversions liées et le repérage des génotypes qui en résultent. Cette variabilité, qui semble persister sous forme d'un polymorphisme équilibré dans ces petites populations insulaires isolées, est au moins aussi importante que celle qu'on observe dans des dèmes comparables d'espèces continentales.

variabilité chromosomique / petite population / biologie insulaire / inversion / Drosophila silvestris 


\section{INTRODUCTION}

The island of Hawaii is less than half a million years old (Moore and Clague, 1992). Drosophila silvestris (Perkins) is endemic to the island and thus has been inferred to be a young autochthonous species (Carson, 1982). Using chromosomal sequences, the origin of this species can be traced phylogenetically through forms on slightly older Hawaiian islands back to ancestors on the island of Kauai, which is about five million years old. When population genetic data on $D$ silvestris from many populations around the island are analyzed quantitatively by hierarchical $F$ statistics, high levels of local genetic differentiation are revealed (Craddock and Carson, 1989). Local demes are small, distinct and restricted demographically, ecologically and altitudinally.

Periodic destruction of older forested areas by lavas on the currently growing shield volcanoes requires such a species to be continually recolonizing. This imposes a metapopulation structure (Carson et al, 1990). The species shows high variability for inversions and isozymes (Craddock and Johnson, 1979) as well as geographical variation for morphological characters, including some that are related to courtship behavior (Carson, 1982).

Variation due to chromosomal inversions in this species is spread over 4 of the 5 major chromosomes of the genome. Using a new method that permits recognition of chromosomal haplotypes, we present a detailed description of the segregating chromosomal variability in this species, using population samples from 2 localized, high-altitude demes.

\section{MATERIALS AND METHODS}

Samples were collected at sites about $9 \mathrm{~km}$ apart on Mauna Kea. The Maulua site is in the North Hilo District at Spring Water Camp (altitude $1539 \mathrm{~m}$ ) in dense Metrosideros-Cibotium forest. The Hakalau site (Hakalau Wildlife Refuge of the United States Fish and Wildlife Service) is near Pua Akala, South Hilo District. At $1890 \mathrm{~m}$, it is not far below the tree line on the mountain and represents the highest altitude from which a sample of this species has been obtained. At this site, there is an overstory of large Acacia koa and Metrosideros collina trees. Both samples were collected by baiting with fermented mushroom and banana within quite small areas; the most distant baiting positions at each locality were no more than $50 \mathrm{~m}$ apart. Maulua was sampled in January 1979 (Maulua-1) and again in October 1980 (Maulua-2) and Hakalau in March and November 1990, and April 1991. The last 3 samples are homogeneous $(P>0.25)$ and have been pooled. The gametic frequencies of the inversions at Maulua were reported by Craddock and Carson (1989); the present paper presents an extension of the analysis to include haplotype data, as explained below.

In both populations, segregating inversions are present in chromosomes $\mathrm{X}, 2,3$ and 4 ; most of these are geographically widespread entities in the species. This paper concentrates particularly on variation in chromosome 4 . In both populations, 5 inversions segregating in substantial frequencies are present. A feature of this study is the development of methods to determine the haplotype frequencies (linkage relationships) in both chromosomes 3 and 4 . These chromosomes carry multiple 
inversions, most of which are separable by crossing over in the visibly large sections of chromosome between the inversions (fig 1).
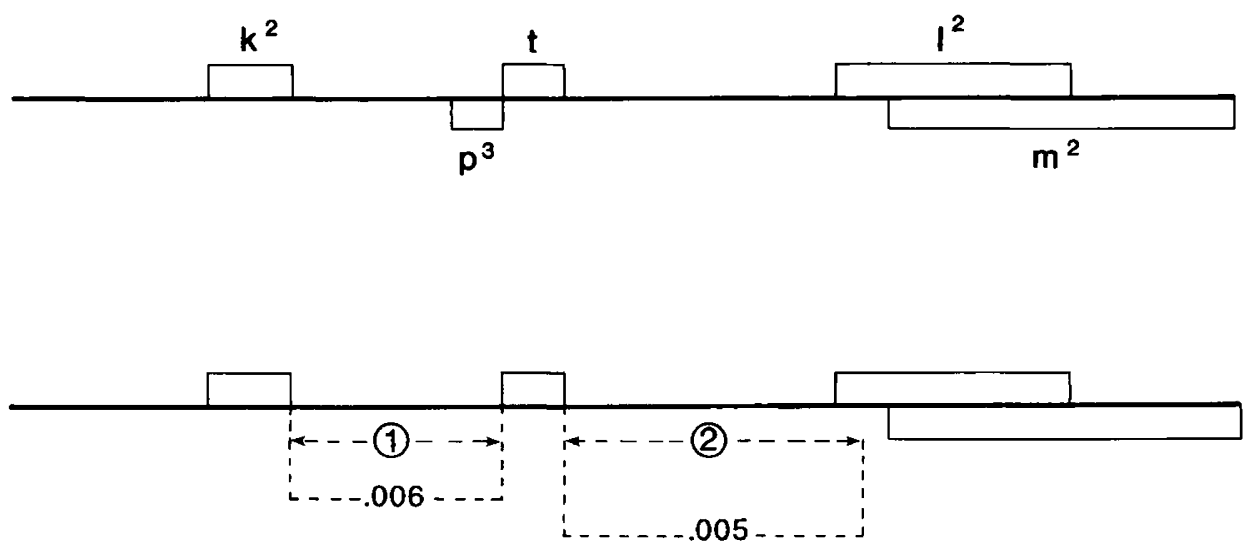

Fig 1. Diagrams of polytene chromosome 4 of $D$ silvestris. The distal end is to the left. Top: names, lengths and relative positions of the five naturally occurring inversions. Bottom: the extent of inter-inversion regions 1 and 2 (dashed lines with arrows) and the amount of crossing over between adjacent inversions observed in double or triple heterozygotes involving these regions.

Each wild specimen was separated by sex at capture and was brought to the laboratory and analyzed separately. Wild males were crossed to females of laboratory stock T94X, which is homokaryotypic for gene arrangement $(\mathrm{X}, 2,3 \mathrm{~m}$, $4 \mathrm{k}^{2}, 4 \mathrm{t}, 5$ : this formula should be read 'homozygous standard $\mathrm{X}$, standard 2, standard 5, homozygous for inversion $\mathrm{m}$ in chromosome 3 and homozygous for inversions $\mathrm{k}^{2}$ and $\mathrm{t}$ in chromosome $\left.4^{\prime}\right)$. Examination of routine aceto-orcein smears of the salivary gland chromosomes of at least $7 \mathrm{~F}_{1}$ larvae was then used to infer the chromosomal composition of each wild male. The lack of crossing over in the male (see Carson and Wisotzkey, 1989) permits a direct reading of the sequence of each chromosome as it occurred in the wild population.

The analysis of females was accomplished by obtaining progeny from each wild specimen (isofemale method) and inferring 2 parental zygotic karyotypes from the wild from the composition of 12 or more $F_{1}$ progeny. In prior studies, many sequential combinations have remained ambiguous because of tight synapsis of the homologues and thus could not be recorded. In this study, 2 methods were used that permitted accurate diagnosis of all sequential haplotypes present in the wild parents. First, in almost every chromosome smear it was observed that in a small number of cells, usually passed over in routine analysis, the 2 homologous members of a polytene chromosome had fortuitously separated from one another, at least in part. Accordingly, the sequence of at least one of these asynapsed strands could be read by direct visual sequencing of the banding order. Reading of one such homologue permits the inference of the sequence of the other. Second, it was possible to remate wild females to T94X males without introducing ambiguity. These wild populations have such low frequencies of homozygous inverted arrangements in chromosomes 3 
and 4 that the paternal contribution of each chromosome of the laboratory stock is effectively marked.

Accordingly, these methods permit the inference, from a single isofemale, of 2 complete 'wild' zygotic karyotypes. Where the laboratory sperm is accepted by the wild female after progeny has already been produced from a wild male, it is possible to infer which zygotic combination represents that of the wild female. Analysis is facilitated by the fact that sperm precedence in $D$ silvestris by the second male (P2) is above $80 \%$ (Wisotzkey and Carson 1986). Two cases of multiple insemination by a second wild male were recognized in this study.

\section{RESULTS}

Table I gives gametic frequencies of the inversions present without regard to their association with one another. The frequency of inversion $41^{2}$ differs between the Maulua-1 and Maulua-2 samples $(P \leqslant 0.001)$. Tables II and III give the frequencies of the haplotypes observed in chromosomes 3 and 4 , respectively. In the latter, the 5 inversions form 3 regional groups over the length of the chromosome: $\mathrm{k}^{2}$ is distal: $\mathrm{t}$ and $\mathrm{p}^{3}$ act as alleles in segregation and are central; $\mathrm{l}^{2}$ and $\mathrm{m}^{2}$ are allelic and proximal (fig 1; see also photograph in Carson 1987). Crossing over within regions 1 and 2 in triple heterozygotes is rare (9/1586 and $7 / 1521$, respectively) when the zygote is $\mathrm{t} /+$ in the center. In 2 instances, however, data were obtained on crossing over in females from informative karyotypes 8/11 and 7/12 (see table III). Both of these are $t / t$ in the mid-region of the chromosome, affording observation of crossovers in an enlarged central homokaryotypic section (regions $1+2$; fig 1 ). The first of these data sets was obtained from a virgin laboratory female from stock U34B4 (Kohala Mountains) crossed to a known homokaryotypic male. The progeny showed 14 crossovers in 50 observed gametes (0.28). A second case (karyotype 7/12) was found in a wild female from Hakalau. Of 18 gametes observed, 8 were crossovers (0.44). Although these data are sparse, they demonstrate that intrachromosomal recombination among the inversions in chromosome 4 occurs and can account for the presence of some rare haplotypes in the population. The theoretical maximum number of haplotypes in chromosome 4 generated by such crossing over is $18 ; 16$ of these have been observed at Maulua and 14 at Hakalau. In chromosome 3, only 3 haplotypes, of a possible 4 , have been observed.

Table IV lists the inversion genotypes observed in the 3 samples and their frequencies. The number $(N)$ of different inversion genotypes theoretically possible from each sample given at the bottom of the table is calculated as $N=k(k+1) / 2$, where $k$ represents the number of chromosome 4 haplotypes observed in each sample. Even in the larger sample from Hakalau, only a little more than one-third $(0.38)$ of the possible variation has been revealed.

In order to test for conformance to expectation under the Hardy-Weinberg equilibrium, the observed inversion genotypes of chromosome 4 listed in table IV have been divided into 4 classes, those that are homokaryotypic, and those that are heterokaryotypic for 1, 2 or 3 inversions (table V). For the chi-square values given in this table, the number of degrees of freedom is given as two (2). Conservatively, this number might be viewed as less than this, since some of the haplotypes are related by recombination. If only one degree of freedom were allowable, however, the 
Table I. Frequency of 11 inversions observed in single local populations of $D$ silvestris in samples from Maulua and Hakalau, Mauna Kea, Hawaii.

\begin{tabular}{lccc}
\hline Inversion & Maulua-1 & Maulua-2 & Hakalau \\
\hline $\mathrm{Xo}^{3}$ & - & 0.043 & 0.032 \\
$\mathrm{Xt}^{3}$ & 0.083 & 0.085 & 0.022 \\
$2 \mathrm{t}$ & 0.031 & 0.026 & - \\
$2 \mathrm{o}$ & 0.063 & 0.066 & 0.184 \\
$3 \mathrm{~m}$ & 0.406 & 0.382 & 0.176 \\
$3 \mathrm{r}$ & 0.063 & 0.132 & 0.022 \\
$4 \mathrm{k}^{2}$ & 0.406 & 0.487 & 0.154 \\
$4 \mathrm{p}^{3}$ & 0.125 & 0.118 & 0.257 \\
$4 \mathrm{t}$ & 0.625 & 0.697 & 0.449 \\
$4 \mathrm{l}^{2}$ & 0.563 & 0.197 & 0.419 \\
$4 \mathrm{~m}^{2}$ & 0.125 & 0.289 & 0.279 \\
$\mathrm{Total}^{2}$ & & & \\
$N^{a}$ & 32 & 76 & 93 \\
$N^{x}$ & 24 & 47 & \\
\hline
\end{tabular}

$N^{a}$ and $N^{x}$ are the number of autosomes and X-chromosomes scored, respectively.

Table II. Frequency of inversion haplotypes in chromosome 3.

\begin{tabular}{cccccc}
\hline & $\begin{array}{c}\text { Sequence } \\
\text { formula }\end{array}$ & $\begin{array}{c}\text { Shorthand } \\
\text { designation }\end{array}$ & Maulua-1 & Maulua-2 & Hakalau \\
\hline+ & + & 1 & 0.594 & 0.618 & 0.824 \\
+ & $\mathrm{r}$ & 2 & $-\mathrm{a}$ & $-\mathrm{a}$ & $-\mathrm{a}$ \\
$\mathrm{m}$ & + & 3 & 0.344 & 0.250 & 0.154 \\
$\mathrm{~m}$ & $\mathrm{r}$ & 4 & 0.063 & 0.132 & 0.022 \\
\multicolumn{2}{l}{ Total observed } & & 32 & 76 & 136 \\
\hline
\end{tabular}

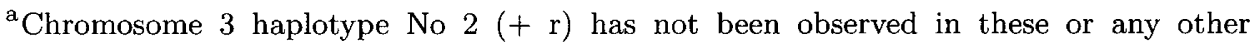
populations.

deviations from expectation by Maulua-1 and Hakalau would be only of marginal significance at the $5 \%$ level. We conclude that the observed numbers do not depart significantly from expectation.

Inversion genotypes in chromosome 3 were also compared with expectation based on the frequencies of the 3 haplotypes (table VI). There appears to be no deviation from expectation.

\section{DISCUSSION}

Chromosomal polymorphism in $D$ silvestris has been shown to be reasonably high throughout the distribution of the species, which shows striking altitudinal clines as well (Craddock and Carson, 1989). This polymorphism is accompanied by considerable electrophoretic variation (Craddock and Johnson, 1979). What is remarkable 
Table III. Frequencies of 18 inversion haplotypes in chromosome 4 at Maulua and Hakalau, Hawaii.

\begin{tabular}{|c|c|c|c|c|c|c|}
\hline \multicolumn{3}{|c|}{ Sequence formula } & \multirow{2}{*}{$\begin{array}{c}\text { Shorthand designation } \\
1\end{array}$} & \multirow{2}{*}{$\frac{\text { Maulua-1 }}{0.031}$} & \multirow{2}{*}{$\frac{\text { Maulua-2 }}{0.013}$} & \multirow{2}{*}{$\begin{array}{c}\text { Hakalau } \\
0.051\end{array}$} \\
\hline+ & + & + & & & & \\
\hline $\mathrm{k}^{2}$ & + & + & 2 & 0.031 & 0.026 & 0.022 \\
\hline+ & + & $\mathrm{l}^{2}$ & 3 & 0.094 & 0.026 & 0.169 \\
\hline $\mathrm{k}^{2}$ & + & $1^{2}$ & 4 & 0.094 & 0.026 & 0.022 \\
\hline+ & + & $\mathrm{m}^{2}$ & 5 & - & 0.026 & 0.030 \\
\hline $\mathrm{k}^{2}$ & + & $\mathrm{m}^{2}$ & 6 & - & 0.013 & - \\
\hline+ & $\mathrm{t}$ & + & 7 & 0.125 & 0.184 & 0.125 \\
\hline $\mathrm{k}^{2}$ & $\mathrm{t}$ & + & 8 & 0.031 & 0.250 & 0.037 \\
\hline+ & $\mathrm{t}$ & $\mathrm{l}^{2}$ & 9 & 0.187 & 0.040 & 0.044 \\
\hline$k^{2}$ & $\mathrm{t}$ & $\mathrm{l}^{2}$ & 10 & 0.156 & 0.053 & 0.015 \\
\hline+ & $\mathrm{t}$ & $\mathrm{m}^{2}$ & 11 & 0.063 & 0.119 & 0.169 \\
\hline $\mathrm{k}^{2}$ & $\mathrm{t}$ & $\mathrm{m}^{2}$ & 12 & 0.063 & 0.092 & 0.059 \\
\hline+ & $p^{3}$ & + & 13 & 0.094 & 0.040 & 0.066 \\
\hline $\mathrm{k}^{2}$ & $\mathrm{p}^{3}$ & + & 14 & - & - & $-{ }^{a}$ \\
\hline+ & $\mathrm{p}^{3}$ & $\mathrm{l}^{2}$ & 15 & 0.031 & 0.026 & 0.169 \\
\hline $\mathrm{k}^{2}$ & $\mathrm{p}^{3}$ & $1^{2}$ & 16 & - & 0.040 & - \\
\hline+ & $\mathrm{p}^{3}$ & $\mathrm{~m}^{2}$ & 17 & - & 0.026 & 0.022 \\
\hline $\mathrm{k}^{2}$ & $\mathrm{p}^{3}$ & $\mathrm{~m}^{2}$ & 18 & - & - & $-^{a}$ \\
\hline \multicolumn{3}{|c|}{ Total observed } & & 32 & 76 & 136 \\
\hline
\end{tabular}

${ }^{a}$ Haplotypes 14 and 18 have not been found in these or any other populations.

about the populations described here is the almost genome-wide distribution of the chromosomal polymorphism. Chromosome 5 is monomorphic throughout this species and also in the other 4 members of its cluster of closely related species on Hawaii, Maui, Molokai and Oahu. The polymorphism in these demes is highlighted by its extensive nature in chromosome 4, in which 16 (Maulua-2) and 14 (Hakalau) haplotypes have been recognized and their zygotic combinations observed.

Compared with a well-studied case of a continental species (table VII), it is clear that the current populations of this newly formed insular species are far from depauperate in genetic variation. Indeed, this tendency is even expressed in altitudinally marginal populations such as the one described from Hakalau. These findings confirm earlier estimates for other Hawaiian species (Ayala 1975; Craddock and Johnson 1979).

What forces within these small populations are responsible for the retention of this variability? The data from the analysis of the haplotypes of chromosome 4 suggest that they combine at random at syngamy according to the Hardy-Weinberg equilibrium and that no major viability differences are apparent between the various genotypic combinations. 
Table IV. Inversion genotypes formed by chromosome 4 haplotypes as observed in samples from Maulua and Hakalau.

\begin{tabular}{|c|c|c|c|c|c|c|c|}
\hline \multirow{2}{*}{$\begin{array}{l}\text { Genotype } \\
\text { formula }\end{array}$} & \multicolumn{2}{|c|}{ Maulua } & \multirow[t]{2}{*}{ Hakalau } & \multirow{2}{*}{$\begin{array}{l}\text { Genotype } \\
\text { formula }\end{array}$} & \multicolumn{2}{|c|}{ Maulua } & \multirow[t]{2}{*}{ Hakalau } \\
\hline & -1 & -2 & & & -1 & -2 & \\
\hline $1 / 3$ & - & - & 1 & $7 / 7$ & - & 2 & 1 \\
\hline $1 / 5$ & - & - & 1 & $7 / 8$ & - & 6 & - \\
\hline $1 / 9$ & - & - & 1 & $7 / 9$ & - & - & 1 \\
\hline $1 / 11$ & - & - & 2 & $7 / 10$ & - & - & 1 \\
\hline $1 / 13$ & 1 & - & 1 & $7 / 11$ & 1 & 1 & 3 \\
\hline $1 / 15$ & - & - & 1 & $7 / 12$ & - & 2 & 2 \\
\hline \multirow[t]{2}{*}{$1 / 16$} & - & 1 & - & $7 / 13$ & 1 & 1 & 2 \\
\hline & & & & $7 / 15$ & - & - & 4 \\
\hline $2 / 3$ & - & - & 1 & & & & \\
\hline $2 / 8$ & - & 1 & - & $8 / 8$ & - & 2 & - \\
\hline $2 / 9$ & - & 1 & - & $8 / 9$ & 1 & - & - \\
\hline $2 / 11$ & - & - & 1 & $8 / 11$ & - & 3 & - \\
\hline $2 / 12$ & - & - & 1 & $8 / 12$ & - & 1 & - \\
\hline $2 / 13$ & 1 & - & - & $8 / 15$ & - & 1 & 1 \\
\hline $3 / 3$ & 1 & - & 3 & $9 / 10$ & 4 & 1 & - \\
\hline $3 / 4$ & - & - & 1 & $9 / 11$ & - & - & 1 \\
\hline $3 / 7$ & - & - & 2 & $9 / 12$ & 1 & - & - \\
\hline $3 / 8$ & - & 1 & 2 & $9 / 13$ & - & 1 & 1 \\
\hline $3 / 10$ & 1 & - & - & $9 / 15$ & - & - & 1 \\
\hline $3 / 11$ & - & - & 3 & $9 / 17$ & - & - & 1 \\
\hline $3 / 12$ & - & - & 3 & & & & \\
\hline $3 / 13$ & - & - & 2 & $10 / 11$ & - & 2 & 1 \\
\hline $3 / 15$ & - & - & 2 & $10 / 12$ & - & 1 & - \\
\hline \multirow[t]{2}{*}{$3 / 17$} & - & 1 & - & & & & \\
\hline & & & & $11 / 11$ & - & - & 1 \\
\hline $4 / 7$ & 2 & - & - & $11 / 13$ & - & - & 1 \\
\hline $4 / 8$ & - & 1 & - & $11 / 15$ & - & 1 & 6 \\
\hline $4 / 11$ & 1 & - & 1 & $11 / 17$ & - & 1 & 2 \\
\hline $4 / 12$ & - & 1 & - & & & & \\
\hline \multirow[t]{2}{*}{$4 / 13$} & - & - & 1 & $12 / 13$ & - & 1 & - \\
\hline & & & & $12 / 15$ & 1 & - & 2 \\
\hline $5 / 8$ & - & 1 & 2 & $12 / 16$ & - & 1 & - \\
\hline $5 / 11$ & - & 1 & - & & & & \\
\hline $5 / 15$ & - & - & 1 & $13 / 15$ & - & - & 1 \\
\hline $6 / 16$ & - & 1 & - & $15 / 15$ & - & - & 2 \\
\hline
\end{tabular}

Respectively, for Maulua ( -1 and -2 ) and Hakalau: total number of genotypes observed: $16,38,68$; number of different genotypes observed: $12,27,40$; number of different genotypes theoretically possible: $78,136,105$. 
Table V. Gross distribution of adult inversion genotypes observed in chromosome 4 compared with expectation based on observed haplotype frequencies.

\begin{tabular}{|c|c|c|c|c|c|}
\hline & \multicolumn{4}{|c|}{ Number of heterozygous inversions } & \multirow[t]{2}{*}{ Total } \\
\hline & 0 & 1 & 2 & 3 & \\
\hline \multicolumn{6}{|l|}{ Maulua-1 } \\
\hline Observed & 1 & 7 & 4 & 4 & 16 \\
\hline Expected & 1.81 & 6.03 & 6.25 & 1.91 & 16.00 \\
\hline \multicolumn{6}{|c|}{ For Maulua-1: $\chi^{2}=3.616 ; d f^{\mathrm{a}}=2 ; P=0.17$} \\
\hline \multicolumn{6}{|l|}{ Maulua-2 } \\
\hline Observed & 4 & 14 & 14 & 6 & 38 \\
\hline Expected & 4.98 & 9.69 & 17.99 & 5.34 & 38.00 \\
\hline \multicolumn{6}{|c|}{ For Maulua-2: $\chi^{2}=3.077 ; d f^{a}=2 ; P=0.25$} \\
\hline \multicolumn{6}{|l|}{ Hakalau } \\
\hline Observed & 7 & 17 & 31 & 13 & 68 \\
\hline Expected & 8.0 & 22.0 & 29.7 & 8.3 & 68.0 \\
\hline \multicolumn{6}{|c|}{ For Hakalau: $\chi^{2}=3.97 ; d f^{\mathrm{a}}=2 ; P=0.14$} \\
\hline
\end{tabular}

${ }^{a}$ For explanation of degrees of freedom, see text.

Table VI. Distribution of inversion genotypes observed in chromosome 3 compared with expectation based on observed haplotype frequencies. Rare homokaryotypes $3 / 3$ and $4 / 4$ were combined.

\begin{tabular}{|c|c|c|c|c|c|c|}
\hline & \multicolumn{2}{|c|}{ Homokaryotype } & \multicolumn{3}{|c|}{ Heterokaryotype } & \multirow[t]{2}{*}{ Total } \\
\hline & $1 / 1$ & $3 / 3$ and $4 / 4$ & $1 / 3$ & $1 / 4$ & 3.4 & \\
\hline \multicolumn{7}{|l|}{ Maulua-1 } \\
\hline Observed & 5 & 2 & 7 & 2 & 0 & 16 \\
\hline Expected & 5.6 & 2.0 & 6.5 & 1.2 & 0.7 & 16.0 \\
\hline \multicolumn{7}{|c|}{$\chi^{2}=1.34 ; d f=3 ; P>0.7$} \\
\hline \multicolumn{7}{|l|}{ Maulua-2 } \\
\hline Observed & 14 & 1 & 13 & 6 & 4 & 38 \\
\hline Expected & 14.5 & 3.0 & 11.8 & 6.2 & 2.5 & 38.0 \\
\hline \multicolumn{7}{|c|}{$\chi^{2}=2.41 ; d f=3 ; P>0.5$} \\
\hline \multicolumn{7}{|l|}{ Hakalau } \\
\hline Observed & 44 & 0 & 21 & 3 & 0 & 68 \\
\hline Expected & 46.1 & 1.7 & 17.3 & 2.5 & 0.4 & 68.0 \\
\hline \multicolumn{7}{|c|}{$\chi^{2}=3.12 ; d f=3 ; P>0.35$} \\
\hline
\end{tabular}

Four of these chromosome 4 haplotypes from a different geographical area, however, have been studied in laboratory experiments (Carson 1987; Carson and Wisotzkey 1989). Viability differences in the laboratory also appear to be minimal. 
Table VII. Number of inversion genotypes possible for females in a deme from a continental species ( $D$ robusta, Olivette, Missouri ${ }^{\mathrm{a}}$ ) compared with that of an insular species ( $D$ silvestris, Maulua-2, Hawaii).

\begin{tabular}{lrrlrrrr}
\hline & \multicolumn{4}{c}{ Chromosomal element (Muller 1940) } & Total \\
\cline { 2 - 6 } & $A$ & $B$ & $C$ & $D$ & \multicolumn{1}{c}{$E$} & \\
\hline Olivette, Missouri & 10 & 3 & 3 & 6 & 6 & 3240 \\
Maulua-2, Hawaii & 6 & 6 & 6 & 1 & 136 & 29376 \\
\hline
\end{tabular}

${ }^{\mathrm{a}}$ Data from Carson (1958).

Homokaryotypes, however, were greatly under-represented relative to heterokaryotypes among those flies that bred successfully in the laboratory. Accordingly, we suggest that a comparable heterotic reproductive success may occur in these more complex natural populations, making this yet another case of differential reproduction favoring heterokaryotypic individuals. As each inversion covers a substantial section of chromosome, the amount of genic heterozygosity retained is also expected to be large.

Although these insular populations of $D$ silvestris have been apparently naturally subjected to repeated recolonizations and bottlenecks on these growing shield volcanoes, they nevertheless appear to retain a large amount of genetic variability that is manifested even in marginal, relatively isolated demes.

\section{ACKNOWLEDGMENTS}

We thank K Kaneshiro, W Perreira and C Simon for assisting in the collecting and L Freed and R Cann for logistical support in the field. R Wass, of the Fish and Wildlife Service kindly issued a Special Use permit for the collections in the Hakalau Forest Reserve. T Lyttle and R Wisotzkey gave valuable advice on statistical matters. We are also grateful for the work of $\mathrm{L}$ Teramoto Doescher, who reared the larvae and made the chromosome smears. Work supported by NSF grant BSR 84-15633 to the University of Hawaii.

\section{REFERENCES}

Ayala FJ (1975) Genetic differentiation during the speciation process. Evol Biol 8, 1-78

Carson HL (1958) The population genetics of Drosophila robusta. Adv Genet 9, 1-40

Carson HL (1982) Evolution of Drosophila on the newer Hawaiian volcanoes. Heredity 48, $3-25$

Carson HL (1987) High fitness of heterokaryotypic individuals segregating naturally within a long-standing laboratory population of Drosophila silvestris. Genetics 116, 415-422

Carson HL, Lockwood JP, Craddock EM (1990) Extinction and recolonization of local populations on a growing shield volcano. Proc Natl Acad Sci USA 87, 7055-7057

Carson HL, Wisotzkey RG (1989) Increase in genetic variance following a population bottleneck. Am Nat 134, 668-673

Craddock EM, Carson HL (1989) Chromosomal inversion patterning and population differentiation in a young insular species, Drosophila silvestris. Proc Natl Acad Sci USA 86, 4798-4802 
Craddock EM, Johnson WE (1979) Genetic variation in Hawaiian Drosophila. V. Chromosomal and allozymic diversity in Drosophila silvestris and its homosequential species. Evolution 33, 137-155

Moore JM, Clague DA (1992) Volcano growth and evolution of the island of Hawai. Bull Geol Soc Am 104, 1471-1484

Muller HJ (1940) Bearings of the 'Drosophila' work on systematics. In: The New Systematics (J Huxley, ed), Clarendon Press, Oxford, 185-268

Wisotzkey RG, Carson HL (1986) Sperm predominance in Drosophila silvestris. Genetics $113, \mathrm{~s} 46$ 